\title{
ANÁLISE DE DADOS CLÍNICOS E LABORATORIAIS ASSOCIADOS À LITÍASE URINÁRIA EM PACIENTES DE UM LABORATÓRIO DE ANÁLISES CLÍNICAS
}

\section{CLINICAL AND LABORATORY DATA ANALYSIS ASSOCIATED WITH UROLITHIASIS \\ IN PATIENTS IN A CLINICAL LABORATORY}

\author{
Victor José LOPATA ${ }^{1}$, Doroteia Aparecida HÖFELMANN² ${ }^{2}$ Juliana SPEZIA ${ }^{3}$, Aline \\ Borsato HAUSER ${ }^{4}$
}

1 - Farmacêutico Especialista em Análises Clínicas pela Universidade Federal do Paraná (UFPR)

2 - Profa Dra do Departamento de Nutrição da Universidade Federal do Paraná (UFPR)

3 - Profa MSC do Departamento de Análises Clínicas da Universidade Federal do Paraná (UFPR)

4 - Profa Dra do Departamento de Análises Clínicas da Universidade Federal do Paraná (UFPR)

Autora Correspondente: alinehauser@ufpr.br

\section{RESUMO:}

A litíase urinária é uma doença que acomete milhões de pessoas anualmente e se deve à formação de cálculos resultantes da aglomeração de cristais. O exame de urina possibilita a detecção da hematúria e a identificação de cristais. Este trabalho estabeleceu a relação entre os dados clínicos e laboratoriais envolvidos na litíase urinária em um laboratório clínico em Reserva-PR. Os pacientes responderam questionário sobre os dados clínicos e a partir das amostras de urina foram identificados cristais e quantificadas hemácias. Do total de pacientes $(n=400), 27 \%$ apresentaram cristais. Houve predomínio de oxalato de cálcio (65\%), seguido por uratos amorfos, ácido úrico, carbonato de cálcio e fosfatos amorfos. Houve resultado significativo $(p<0,001)$ quando associados presença de cristal e evidência clínica, sendo comparados aos pacientes sem e com histórico. Não houve diferença significativa quando comparada hematúria com presença de cristais, evidência ou histórico. A hematúria pode ser sinal de litíase e o achado de aglomerados de cristais, pode ser indicativo. Em nosso trabalho, a incidência de cristalúria e a prevalência de oxalato de cálcio condizem com a literatura. A associação entre presença de cristais, evidência e histórico evidenciaram a importância do histórico na litíase. Não se pode afirmar que a hematúria encontrada teve relação direta com o aparecimento dos cristais, ou que os pacientes com hematúria e sem cristais não apresentavam cálculo. Concluindo, estas investigações são importantes para melhor elucidar os aspectos clínicos e laboratoriais na litíase, evitar casos novos ou impedir que pacientes já afetados tenham recidivas.

Palavras-chave: urolitíase, urinálise, cristalúria e hematúria.

\section{ABSTRACT}

Urolithiasis is disease that affects millions of people annually and is due to stone formation resulting from the crystal agglomeration. Urinalysis allows detection of hematuria and the identification of crystals. This work established the relationship between the clinical and laboratory data in the development of lithiasis in clinical laboratory Reserva, PR. The patients answered a questionnaire about clinical data. Crystals were identified and red blood cells were quantified from urine samples. Regarding patients $(n=400), 27 \%$ showed crystals. 
There was a predominance of calcium oxalate $(65 \%)$, followed by urates, uric acid, carbonate and phosphates. Patients were assessed for clinical evidence and crystals with significant results $(p<0.001)$ compared with and without history. There was no significant difference when compared hematuria and crystals, evidence or history. Hematuria may be lithiasis signal and the finding of crystal clusters can be indicative. In our study, the incidence of crystalluria and the prevalence of calcium oxalate consistent with the literature. The association between the presence of crystals, evidence and history showed the importance of history on lithiasis. We cannot say that hematuria found was directly related to the appearance of crystals, or patients with hematuria and no crystals had no lithiasis. In conclusion, these investigations are important to further elucidate the clinical and laboratory aspects of urolithiasis, prevent new cases or prevent patients affected already have relapses.

Keywords: urolithiasis, urinalisys, crystals in urine, red blood cells in urine.

\section{INTRODUÇÃO}

A litíase urinária ou nefrolitíase é uma doença que acomete milhões de pessoas anualmente e se deve à formação de cálculos no interior do cálice renal, na pelve renal, nos ureteres ou na bexiga. Os cálculos urinários são estruturas sólidas que resultam da aglomeração de cristais que se formam devido a uma alteração bioquímica. A permanência de cálculos no aparelho urinário pode ser assintomática ou desencadear sintomas como dor (cólica renal), hematúria, obstrução e predisposição à infecção urinária. Tais situações, se não tratadas, podem levar a complicações clínicas graves, e até mesmo progredir para a perda irreversível da função renal (BARROS, 2006) (CRUZ, 2008).

A litíase urinária é uma doença milenar que acomete a humanidade desde os seus primórdios e com alta prevalência, sendo estimada em 10 a 12\% da população. História familiar é frequentemente observada sendo que estes pacientes apresentam duas vezes mais chance de desenvolver a doença. Pode atingir qualquer fase da vida, porém tem pico de incidência entre os 20 e 40 anos de idade e o gênero masculino tem cerca de duas a três vezes mais chance de apresentar litíase. A taxa de recorrência é de 50\%, após 5-10 anos do primeiro episódio, se os pacientes não forem submetidos a nenhum tratamento, e de 75\% em 20 anos (TOSTES, 2001) (GOMES, 2005) (HAN et al., 2015) (CRUZ, 2008).

A partir da década de 80 , as técnicas menos invasivas de tratamento, como a litotripsia extracorpórea e o desenvolvimento de técnicas endoscópicas, começaram a ser mais difundidas, reduzindo os danos causados à saúde e a taxa de mortalidade ocasionada pela doença. Mas, ainda é uma patologia que poderia ser mais investigada, tendo em vista que com o avanço tecnológico houve uma diminuição das ações voltadas para a prevenção que depende de ações mais simples, baratas e com alta eficácia, dando-se mais 
importância ao tratamento que é complexo, oneroso e nem sempre totalmente eficaz (GOMES, 2005) (BARROS, 2006).

O exame parcial de urina é realizado rotineiramente nos laboratórios de análises clínicas, sendo simples, com custo relativamente baixo e coleta não invasiva. No caso da litíase urinária, o parcial de urina possibilita a detecção da hematúria microscópica e quando na presença de cristais, possibilita a detecção e a identificação dos diferentes tipos de cristais associados ou não à litíase urinária (LIMA, 1999) (STRASINGER, 2009) (BARROS, 2006) (HENNEBERG, 2015). Portanto, este trabalho procurou estabelecer a relação entre os dados clínicos e laboratoriais envolvidos na litíase urinária em pacientes de um laboratório de análises clínicas em Reserva - Paraná.

\section{MATERIAL E MÉTODOS}

Os pacientes participantes responderam a um questionário com as seguintes informações sobre os dados clínicos: Uso de medicamentos nos últimos dias; percepção de desconforto, como dor abdominal, urgência em urinar, esforço ou dor na hora da micção; eventos de febre nos últimos dias; histórico familiar de litíase urinária e evidência de litíase urinária nos últimos seis meses. Foram excluídos do estudo os pacientes que relataram uso de medicamentos ou eventos de febre nos últimos dias que antecederam a pesquisa.

As amostras para realização do exame parcial de urina foram obtidas por meio de coleta convencional da primeira urina da manhã, após higiene íntima e descarte do primeiro jato, sendo excluídas as amostras com característica de infecção das vias urinárias (leucócitos $>10.000 / \mathrm{ml}$, febre ou uso de medicação antibacteriana), período menstrual ou amostras refrigeradas. Após triagem inicial, foram selecionadas 400 pacientes participantes no estudo. Foram centrifugados $10 \mathrm{~mL}$ de urina em centrífuga calibrada em 1630rpm (LABORLINE modelo Omega), equivalente a 400 força centrífuga relativa (FCR), por $5 \mathrm{~min}$. Após, foram retirados $9 \mathrm{~mL}$ do sobrenadante, deixando um precipitado de $1 \mathrm{~mL}$ que foi homogeneizado e colocado em câmara tipo K-Cell囚, para análise em microscopia ótica comum (NIKON®, modelo Alphaphot 2-YS2) em aumento de 400 vezes. Foram analisados 18 círculos da câmara, multiplicando o valor de elementos encontrados por 500 (fator de correção para mililitro). Foram pesquisados cristais conforme suas características de formas geométricas e grau de refringência e associados ao $\mathrm{pH}$. Foram pesquisadas e quantificadas hemácias, sendo que foi relatado "+" entre 6.000 a 10.000/ml, "++" entre 11.000 a $30.000 / \mathrm{ml} \mathrm{e} \mathrm{"+++"} \mathrm{quando}>30.000 / \mathrm{ml}$. 
A análise estatística foi realizada utilizando-se as variáveis categóricas que foram descritas por meio de suas frequências absolutas (n) e relativas (\%). A associação entre as variáveis categóricas foi investigada por meio do teste do qui-quadrado de Pearson. Foram consideradas significativas as diferenças quando valor de $p \leq 0,05$ (Kirkwood, 1988). As análises foram realizadas no programa Stata 12 (KIRKWOOD, 1988).

Todos os pacientes participantes assinaram o Termo de Consentimento Livre e Esclarecido (TCLE) e os procedimentos seguidos nos experimentos estão em consonância com os princípios éticos aceitos pela normativa nacional (Resolução CNS 196/96) e internacional (Declaração de Helsinki/ World Medical Association).

\section{RESULTADOS}

Do total de pacientes participantes $(n=400)$, houve um predomínio do gênero feminino (60,5\%) em relação ao gênero masculino (39,5\%) com faixa etária entre 18 a 40 anos (75\%) e 41 a 60 anos (25\%). Em relação à presença de cristais na urina, $27 \%$ dos pacientes apresentaram cristais $(n=106)$ (Gráfico $1 A)$, sendo 33\% do gênero masculino e $22 \%$ do gênero feminino (Gráfico 1B).

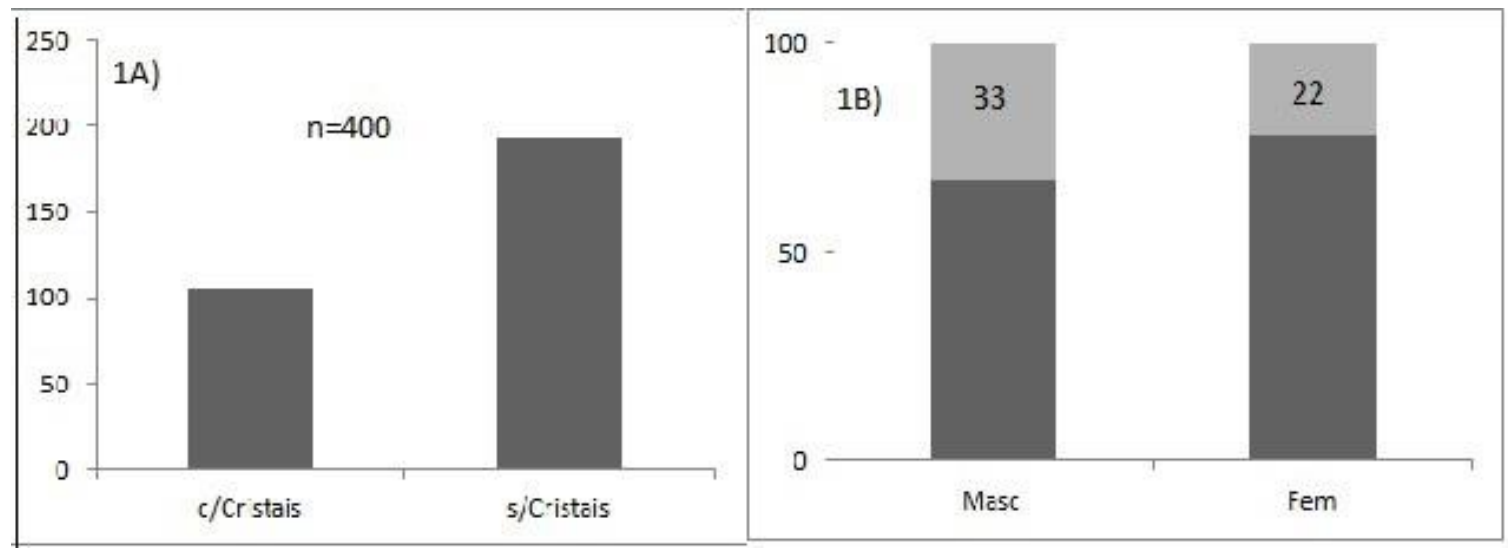

Gráfico 1. Pacientes sem cristais $(n=294)$ ou com cristais independentes do tipo de cristal $(n=106)(1 A)$ e pacientes (\%) conforme o gênero (1B)

Foram encontrados seis tipos diferentes de cristais. De forma isolada houve predomínio dos cristais de oxalato de cálcio (65\%), seguido por uratos amorfos (20\%), ácido úrico (4\%), carbonato de cálcio (3\%) e fosfatos amorfos (1\%). Em relação às amostras que apresentaram mais de um tipo de cristal, também houve prevalência de cristais de oxalato 
de cálcio associado a: uratos amorfos (5\%) e ácido úrico (1\%). Também foram encontrados fosfatos amorfos e fosfato triplo (1\%) conforme Gráfico 2.

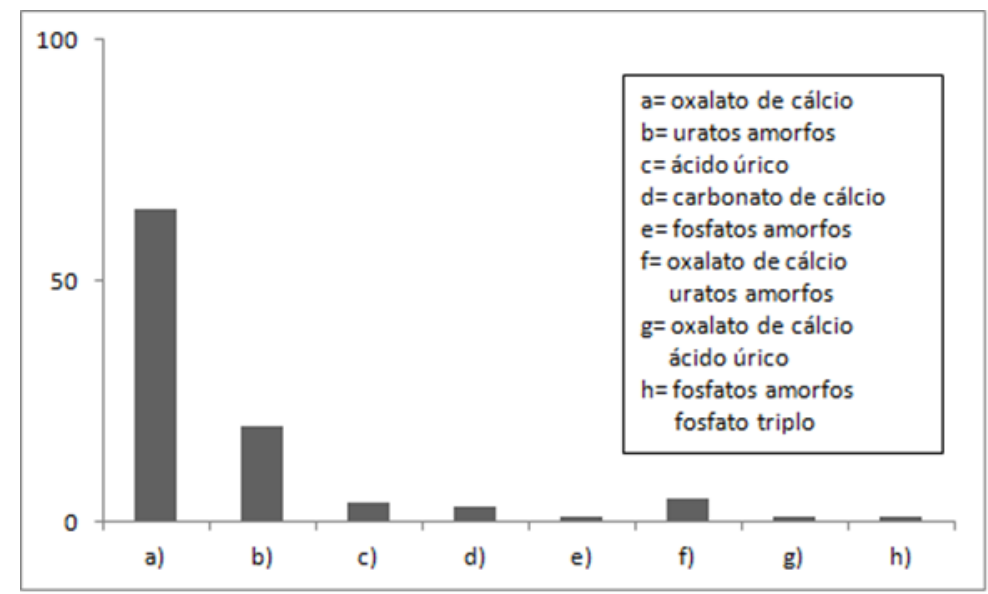

Gráfico 2. Principais tipos de cristais encontrados $(n=106)$

Dos pacientes com cristais ( $n=106)$, 30\% apresentaram histórico de litíase e 13\% apresentaram evidência de litíase nos últimos 6 meses. Quando avaliado o total de pacientes participantes do estudo $(n=400)$ com evidência clínica, os resultados encontrados foram significativos $(p<0,001)$ se comparados os pacientes sem histórico $(5 \%)$ e com histórico (32\%) (Gráfico 3A). Da mesma forma, dos pacientes com cristais e evidência clínica, foram encontrados resultados significativos $(p<0,001)$ quando comparados os pacientes sem histórico (8\%) e com histórico (38\%) (Gráfico 3B).

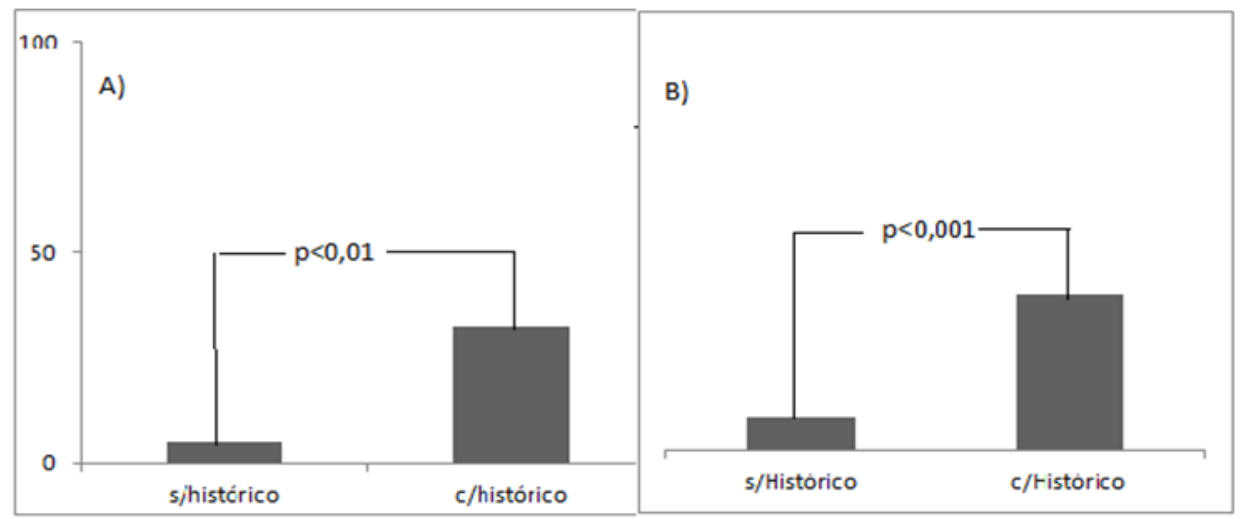

Gráfico 3. Relação significativa entre pacientes com evidência clínica quando comparados sem e com histórico (3A) e entre pacientes com evidência e cristalúria quando comparados sem e com histórico (3B) 
Em relação aos pacientes que apresentaram cristais, 27\% apresentaram hematúria associada e $26 \%$ não apresentaram hematúria $(p=0,869)$ (Gráfico $4 A$ ), sendo que do total de amostras analisadas $(n=400), 9,2 \%$ apresentaram hematúria isolada (sem a presença de cristais). Foi observado que do total de pacientes com evidência de litíase, $20 \%$ apresentou hematúria e 12\% não apresentou $(p=0,152)$ (Gráfico 4B) e do total dos pacientes com histórico, $31 \%$ apresentou hematúria e $30 \%$ não apresentou $(p=0,852)$ (Gráfico 4C).

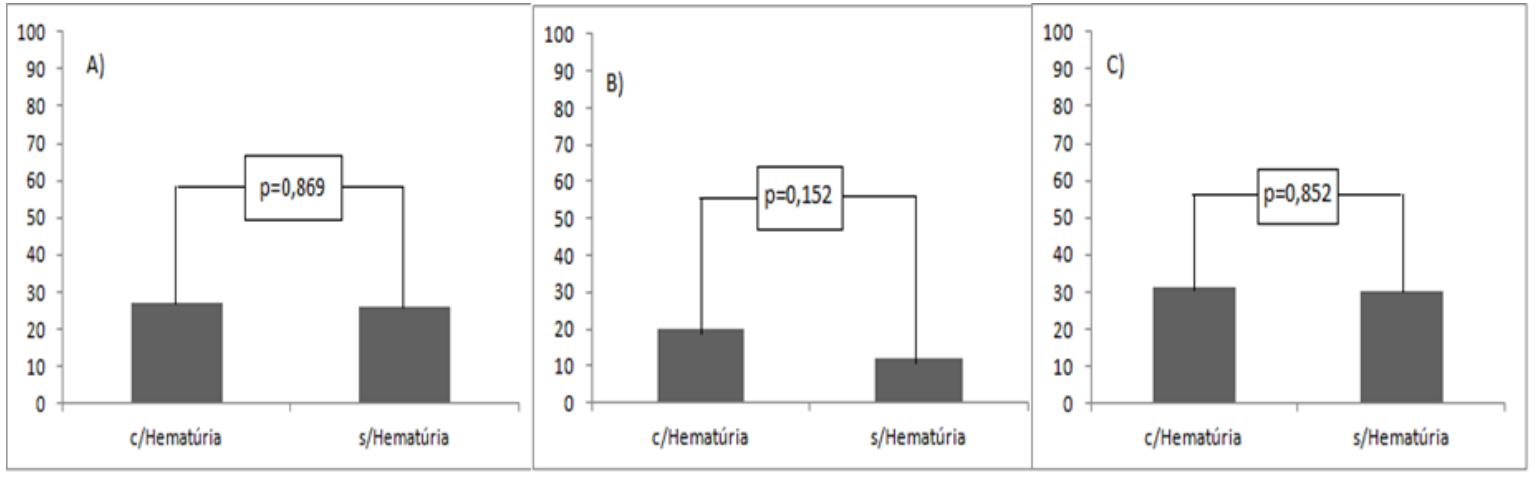

Gráfico 4. Relação de pacientes com e sem hematúria considerando cristalúria (4A), evidência de litíase (4B) e histórico de litíase (4C)

\section{DISCUSSÃO}

Os cristais são formados a partir da precipitação de solutos na urina, de origem orgânica ou inorgânica, mediada por pH, temperatura ou solubilidade. A precipitação in vitro não tem importância clínica e ocorre quando a amostra foi refrigerada ou permaneceu muito tempo em temperatura ambiente (STRASINGER, 2009) (EUROPEAN GUIDELINES, 2000) (HENNEBERG, 2015). Vários fatores contribuem para a formação do cálculo, como hereditariedade, sobrepeso ou obesidade, fatores climáticos e sazonais, sedentarismo, baixa ingestão de líquidos e dieta que favoreça a formação do cálculo (GOMES, 2005). Os demais fatores de risco que elevam as chances de desenvolver a doença incluem as pessoas com alterações anatômicas do trato urinário (duplicidade pielo-calicial, rins policísticos, em ferradura ou espôngio-medular); fatores epidemiológicos (altas temperaturas, utilização de ar-condicionado, dieta hiperproteica, alto consumo de sal ou sedentarismo); diminuição do volume de urina, distúrbios metabólicos (hipercalciúria idiopática, hiperexcreção de ácido úrico, hiperoxalúria, hipomagnesiúria), alterações de pH 
da urina (alcalinização por bactérias produtoras de urease, acidificação por diátese gotosa), imobilização prolongada e utilização de drogas litogênicas (HEILBERG, 2002) (RIBEIRO, 2013).

Sabe-se que um dos fatores que contribuem para a instalação da litíase urinária é a supersaturação do ambiente urinário. As alterações bioquímicas metabólicas levam a um aumento da excreção urinária de substâncias promotoras da formação de cálculos, como cálcio, ácido úrico, oxalato e fosfato ou diminuição da excreção de substâncias inibidoras da cristalização como citrato e magnésio favorecendo o aparecimento na urina de alguns cristais não patológicos, mas que podem influenciar na cristalogênese (GOMES, 2005) (HEILBERG, 2002).

O processo de formação dos cálculos renais é complexo e apresenta divergências entre os autores, mas todos convergem na ideia de que tal processo depende do aumento da concentração de substâncias que estimulem a cristalização e agregação ou por outro lado, da ausência de inibidores na formação dos cristais (TOSTES, 2001). Primeiramente ocorre saturação do ambiente urinário, seguido do processo de nucleação com formação dos cristais, que podem ser liberados livremente na urina. Entretanto, na presença dos fatores que colaboram com o processo, ocorre a agregação, com a junção dos cristais recém-formados, formando aglomerados através de forças intermoleculares. Na última etapa, ocorre retenção e as partículas aglomeradas ficam retidas no sistema coletor. Ainda assim, se forem livremente eliminadas via urina, clinicamente o cálculo não será formado. O cálculo será formado se as partículas retidas crescerem devido a uma tendência físicoquímica pela saturação urinária, aumentando o tamanho do agregado levando a litíase urinária (NARDOZZA JR, 2010).

O achado isolado de cristais na urina não pode ser dito como fator principal para 0 aparecimento de cálculos urinários, mas o achado de aglomerados de cristais assim como a detecção dos cristais "em formação", pode ser indicativo da formação de cálculos renais (HEILBERG, 2002) (VALLADA, 1988) (STRASINGER, 2009). Alguns estudos mostram uma incidência entre 23 a 34\% de cristalúria na população, dependendo da região, hábitos e grupos analisados (SILVA, 2004). Foi observado no nosso estudo que $27 \%$ dos pacientes apresentaram cristais $(n=106)$, sendo $33 \%$ do gênero masculino e $22 \%$ do gênero feminino. Estes dados confirmam o que diz a literatura, que cita um maior risco de desenvolver cálculos renais de até 3 vezes no gênero masculino.

Os cristais de oxalato de cálcio aparecem em ampla faixa de $\mathrm{pH}$ urinário, são birrefringentes sob a luz polarizada e se apresentam nas formas di-hidratada e mono- 
hidratada. Os cristais de ácido úrico e de uratos amorfos são encontrados em pH ácido. Ribeiro e colaboradores determinaram que amostras refrigeradas de urina, além de alterar valores como $\mathrm{pH}$, começam a apresentar cristalúria por precipitação in vitro quando alguns fatores estão associados, como concentração do soluto, $\mathrm{pH}$ e variações de temperatura (RIBEIRO, 2013). Frequentemente, na rotina laboratorial são encontrados cristais, principalmente de uratos amorfos, que se precipitaram devido à exposição à baixa temperatura. No nosso estudo, as amostras refrigeradas foram excluídas e apenas as amostras recém-colhidas e em temperatura ambiente foram analisadas para evitar resultados falsos de cristalúria.

Dentre os cristais de urina alcalina, encontram-se os fosfatos amorfos e os cristais de fosfato amoníaco-magnesiano que geralmente aparecem em urina com grande quantidade de bactéria em pacientes com infecção do trato urinário (ITU). No presente estudo, apenas uma pequena porcentagem dos pacientes apresentou fosfatos amorfos ou fosfatos amorfos associados ao fosfato amoníaco magnesiano, possivelmente porque as amostras com características de ITU foram excluídas. Portanto, como foram excluídos pacientes que apresentavam sintomas ou sinais de infecção urinária e amostras refrigeradas, alguns cristais podem ter sido suprimidos, mas aumentou-se a probabilidade da inclusão de amostras com cristais possivelmente relacionados à formação de litíase.

Aproximadamente $75 \%$ dos cálculos são constituídos por oxalato de cálcio, fosfato de cálcio ou mistura desses (TOSTES, 2001). Segundo Silva et al., os cristais urinários mais comumente encontrados na rotina laboratorial são os de oxalato de cálcio, seguidos pelos cristais de ácido úrico (SILVA, 2004), corroborando com o nosso trabalho que encontrou a maioria dos pacientes $(65 \%)$ com cristais de oxalato de cálcio, embora seguidos por cristais de uratos amorfos (20\%) e ácido úrico (4\%). Lima encontrou cristais de oxalato de cálcio em $76 \%$ dos pacientes portadores de litíase ( $n=2171$ ) (LIMA, 1999). Silva (2004) observou um predomínio de $70 \%$ de cristais de oxalato de cálcio $(n=755)$, nas suas mais variadas formas com predomínio das formas mono-hidratado ou di-hidratado (SILVA, 2004). O nosso trabalho encontrou $65 \%$ de pacientes com cristais de oxalato de cálcio e os demais cristais com um percentual aproximadamente 3 vezes menor. Assim, o porcentual de cristais encontrados no presente trabalho é condizente com os demais trabalhos estudados. Outros cristais não patológicos são fosfato de cálcio, biurato de amônio e carbonato de cálcio. A cristalúria patológica se dá pela presença de cristais que podem representar distúrbios hepáticos, doença renal e desordens metabólicas como os erros inatos do metabolismo. Assim, têm-se os cristais de cistina e estruvita como 
formadores de litíase e outros cristais patológicos como tirosina, leucina, colesterol e bilirrubina (GUIMARÃES, 1990) (NARDOZZA JR, 2010). No nosso estudo não foram encontrados estes tipos de cristais.

Como já comentado, a prevalência da doença fica entre 10 a $12 \%$ da população em geral e Korkes et al. estimam que cerca de 5 a 15\% da população em algum momento da vida irá apresentar cálculos renais (KORKES, 2009), além da alta taxa de recidiva da doença. A litíase tem forte associação com histórico familiar positivo e se estima que aumente em duas vezes as chances de um indivíduo com histórico familiar apresentar a doença (HEILBERG, 2002). Em nosso estudo, 30\% dos pacientes com cristais apresentavam histórico de litíase e 13\% dos pacientes relataram ter apresentado episódio ou evidência da doença nos últimos 6 meses. Os nossos resultados foram significativos $(p<0,001)$ quando avaliado o total de pacientes participantes com evidência clínica e com histórico se comparados aos pacientes com evidência, mas sem histórico. E, os resultados dos pacientes com cristais com histórico e evidência também foram significativos $(p<0,001)$ se comparados aos pacientes com cristais e evidência, mas sem histórico. Tais dados corroboram com a literatura no que diz respeito à importância do histórico do paciente quando se suspeita de litíase. Como nosso trabalho excluiu amostras que poderiam ter cristais formados como artefatos, sugerimos que a presença de pacientes com evidência, cristais na urina e histórico, poderia de fato estar associada à litíase existente ou a uma predisposição a formar novos cálculos. Em relação ao grupo que afirmava apresentar evidência clínica, mas que não tinha histórico nem cristais na urina analisada, talvez outras patologias estejam associadas aos sintomas descritos na avaliação, como problemas musculares ou dores abdominais de outras causas.

Em relação aos pacientes que apresentaram cristais no nosso trabalho, não houve diferença significativa se comparados aos pacientes com ou sem hematúria $(p=0,869)$. Assim como os pacientes com evidência ou com histórico de litíase, quando comparados aos pacientes com ou sem hematúria $(p=0,152$ e $p=0,852$, respectivamente). É de conhecimento que hematúria, principalmente quando microscópica e isomórfica, é um sinal laboratorial de litíase urinária tendo em vista que os cálculos são de natureza rígida e acabam por lesar o epitélio geniturinário. Os nossos resultados não apontaram para um significado estatístico quando se buscou uma relação entre hematúria e presença de cristal, evidência ou histórico, ou seja, não se pode afirmar que a hematúria encontrada em nosso trabalho teve relação direta com o aparecimento dos cristais urinários. Por outro lado, 9\% dos pacientes do nosso estudo apresentaram hematúria isolada (sem a presença de 
cristais), assim não se pode descartar a hipótese destes pacientes não apresentarem cálculo renal, principalmente do gênero masculino. A hematúria pode ser um achado não patológico ou transitório, como no caso do gênero feminino ou outras situações como pósexercício físico vigoroso. Nos casos de hematúria patológica, apesar de ser um achado frequente nos pacientes com litíase, várias outras situações também podem favorecer seu aparecimento, como doenças glomerulares, tumores, traumatismos, pielonefrite e uso de anticoagulantes (STRASINGER, 2009) (BARROS, 2006).

A prevenção dos eventos de litíase urinária é baseada em readequação alimentar como redução do sal e proteína de origem animal assim como aumento da ingesta hídrica, com atitudes por vezes sem custo efetivo e com resultados satisfatórios. Vários fatores dietéticos podem aumentar ou reduzir a incidência de cálculos renais, devendo ser monitorados principalmente nos pacientes que apresentaram episódio da doença ou que tenham histórico familiar positivo. E nos casos da presença de litíase, o tratamento é diferenciado se crise aguda ou litíase recorrente (GOMES, 2005) (HAN et al., 2015) (KORKES, 2009).

Concluindo, o presente estudo estabeleceu uma relação positiva quando se pesquisou "evidência clínica" e "histórico familiar" que foram associados à cristalúria. Sendo assim, estas investigações são importantes para melhor elucidar os aspectos clínicos e laboratoriais na litíase, evitar casos novos ou impedir que pacientes já afetados tenham recidivas.

\section{REFERÊNCIAS}

BARROS, E., MANFRO, RC., THOMÉ, FS, GONÇALVES, LF. , Ed. Nefrologia: rotinas, diagnóstico e tratamento. Porto Alegre: Artmeded. 2006.

CRUZ, J. K., GM.; BARROS, RT. Atualidades em Nefrologia. São Paulo: Sarvier, 2008.

GOMES, P. C., M.; RODRIGUES, M.; VEGA, P.; ROSA, G.; NEVES, J. Profilaxia da litíase renal. Acta Urológica. v. 22(3), p. 47-56. 2005.

GUIMARÃES, R. G., CCC. Interpretação Clínica das Provas Laboratoriais. São Paulo: Sarvier, 1990.

HAN, H. et al. Nutritional Management of Kidney Stones (Nephrolithiasis). Clin Nutr Res. 
v. 4, n.3, p. $137-52.2015$.

HEILBERG, I. S., N.; SANTOS, DR.; CHEIDDE, L.; NORONHA, I. Diretrizes de litíase urinária da Sociedade Brasileira de Nefrologia. J Bras Nefrol. v. 24, p. 203-207. 2002.

HENNEBERG, J. H., R.; NASCIMENTO, AJ.; KUSSEN, G.; BARRETO, FC.; HAUSER, AB. Comparison between Manual Methods and Automated Analyzer iQ200ß (Iris Diagnostics): A Study for the Optimization of Urinalysis. Int J Lab Med Res. v. 2:8, p. 2015.

KIRKWOOD, B. Essentials of medical statistics. Oxford: Blackwell, 1988.

KORKES, F. G., SA.; HEILBERG, IP. Diagnóstico e Tratamento de Litíase Uretral. J Bras Nefrol. v. 31(1), p. 55-61. 2009.

LIMA, W. Relação entre litíase renal, cristais de oxalato de cálcio e hematúria. Revista Sinopse de Urologia. v. 3(4), p. 1999.

NARDOZZA JR, A. Z. F., M.; REIS, RB. Urologia Fundamental. São Paulo: Planmark, 2010.

RIBEIRO, K. S., BRL.; NOLASCO, EL.; VANELLI, CP.; MESQUITA, HL.; CORREAA, JOA. Urine storage under refrigeration preserves the sample in chemical, cellularity and bacteriuria analysis of ACS. J Bras Patol Med Lab. v. 49 (6), p. 415-422. 2013.

SILVA, S. D., M. Cristalúria como um método auxiliar de investigação de pacientes litíásicos: uma experiência na Região Metropolitana de Fortaleza. Revista Brasileira de Análises Clínicas. v. 36(4), p. 233-235. 2004.

STRASINGER, S. D. L., M. Urinalysis and Body Fluids 5. ed. São Paulo: LMP, 2009.

TOSTES, V. C., LR. . Recentes avanços em litíase urinária. J Bras Nefrol. v. 23 (3), p. 166173. 2001.

VALLADA, E. R., AM. Manual de Exames de Urina. Rio de Janeiro: Atheneu, 1988. 